\title{
Zinc as Adjunct Therapy in Neonatal Sepsis
}

\author{
Syed Mortaza Ali*1, Mujibul Hoque ${ }^{2}$, Md. Manajjir Ali ${ }^{3}$, \\ Md. Noor Uddin Talukder ${ }^{4}$, Tanjina Chowdhury ${ }^{5}$
}

\section{Abstract}

Introduction: Altered zinc homeostasis is an important feature of pediatric sepsis, thus raising the possibility of zinc supplementation as a therapeutic strategy in neonatal sepsis, a major source of morbidity and mortality with few therapeutic options beyond antibiotics. Its objective was to find the role of zinc as adjunct therapy in neonatal sepsis. Materials and Methods: This prospective, randomized double blind placebo controlled trial was conducted in the Department of Paediatrics, Sylhet M A G Osmani Medical College, Sylhet, Bangladesh during January 2013 to December 2014. A total 288 neonates with neonatal sepsis were enrolled. Group allocation to either zinc or placebo group was done by lottery method. Each packet contained $5 \mathrm{mg}$ dispersible zinc sulphate or placebo. One packet dissolved in $2 \cdot 5 \mathrm{ml}$ expressed breast milk was given orally or through feeding tube. Results: The age of the patients in zinc group and placebo group was $14.40 \pm$ 6.49 days and $15.09 \pm 7.18$ days respectively. There were $49(75.6 \%)$ male neonates and $16(24.6 \%)$ female neonates in zinc group; while $50(78.1 \%)$ neonates were male and $14(21.9 \%)$ were female in placebo group. Clinical recovery was 61 $(93.8 \%)$ and failure in $4(6.2 \%)$ patients in zinc group; while clinical recovery was 59 (92.2\%) and failure in 5 (7.8\%) patients in placebo group. The mean clinical recovery time in zinc group was $104.20 \pm 16.61$ hours and that of control groups was $111.46 \pm 19.43$ hours. Conclusion: Oral zinc as adjunct therapy shortens the clinical recovery time.

Keywords: Neonatal sepsis, Immunity, Zinc.

Number of Tables: 03; Number of Figures: 02; Number of References: 23; Number of Correspondence: 05.

*1. Corresponding Author:

Dr. Syed Mortaza Ali

MBBS, DCH, MD (Paediatrics)

Resident Physician

Department of Paediatrics

Sylhet MAG Osmani Medical College Hospital, Sylhet.

E-mail : drsmortaza@gmail.com

Mobile no: 01627058165

2. Dr. Mujibul Hoque

MBBS, MD (Paediatrics)

Associate Professor

Department of Paediatrics

Sylhet MAG Osmani Medical College, Sylhet.

3. Prof. Dr. Md. Manajjir Ali

MBBS, FCPS (Paediatrics), DMEd (UK)

Principle \& Professor

Department of Neonatology

North-East Medical College, Sylhet.

4. Dr. Md. Noor Uddin Talukder

MBBS, DCH, MD (Paediatrics)

Assistant Professor

Department of Paediatrics

Sheikh Hasina Medical College, Tangail.

5. Dr. Tanjina Chowdhury

MBBS, MD (Paediatrics)

Assistant Professor

Department of Paediatrics

Sylhet MAG Osmani Medical College, Sylhet.

\section{Introduction}

Sepsis in neonates refers to generalized bacterial infection documented by a positive blood culture in the first 4 weeks of life ${ }^{1}$. It is a major problem in both developed and developing countries. In the developing world, neonatal sepsis remains as the major cause of neonatal mortality and morbidity in spite of recent advances in the investigations and therapeutics ${ }^{2}$.

It is estimated that $20 \%$ of all neonates develop sepsis and is responsible for $30-50 \%$ of total neonatal death in developing countries $^{1}$. It accounts for an estimated 718000 deaths per year or approximately $23.4 \%$ of the world's 3.1 million annual neonatal deaths ${ }^{3}$.

Neonatal sepsis is the term that has been used to describe the systemic inflammatory response syndrome (SIRS) resulting from a suspected or proven infection in the first month of life ${ }^{4}$. Neonatal sepsis contributes to neonatal mortality about $34 \% 0^{5}$. The prevalence of neonatal sepsis is about $20 \%$ in Bangladesh ${ }^{6}$. Of the 7.8 million deaths a year in children younger than 5 years in Africa, South Asia, and the eastern Mediterranean, more than 3 million are in neonates ${ }^{7}$.

According to the time of the acquiring infection, neonatal sepsis is divided as early onset neonatal sepsis (EONS) and late onset neonatal sepsis $(\mathrm{LONS})^{8}$. Among the neonatal sepsis EONS is $77.5 \%$ and LONS is $22.5 \%$.

The spectrum of organisms responsible for early onset neonatal (vertically transmitted) sepsis differs from that associated with late onset neonatal (nosocomial) sepsis. The complications of necrotizing enterocolitis and meningitis predispose an infant to an increased risk of future neurological impairment and the mortality from late onset neonatal sepsis remains high, at $7-10 \%{ }^{10,11}$. 
As bacterial infections predominate in neonatal sepsis so antibiotics is the gold standard therapy for neonatal sepsis ${ }^{11}$.

Early onset sepsis is conventionally regarded as maternally-acquired, with causative organisms, such as Escherichia coli and Group B Streptococcus (GBS) usually found in the maternal genital tract, whereas late onset sepsis is considered environmental in origin-either hospital or community acquired. Commonly implicated organisms in hospital acquired infections are coagulase-negative Staphylococci, Staphylococcus aureus, and Gram-negative organisms such as Klebsiella and Pseudomonas species $^{12}$.

In developed countries Staphylococcus aureus was previously responsible for the majority of late onset infections in many neonatal units with other commonly isolated organisms being coagulase negative Staphylococci, E coli, group B Streptococcus, Klebsiella pneumoniae, Enterococcus, Candida and Pseudomonas. Coagulase negative Staphylococci (CoNS) have now emerged as the leading cause of late onset neonatal sepsis in almost all developed countries and account for $>50 \%$ of positive blood cultures ${ }^{13}$.

In developing countries, the most common gram positive organisms isolated from neonatal blood cultures taken from babies under 90 days of age are Streptococcus pneumoniae, Staphylococcus aureus and Streptococcus pyogenes. The most frequent gram negative organisms isolated are E coli and Salmonella spp ${ }^{14}$.

Early intervention is extremely necessary to prevent deaths and complications due to neonatal sepsis. History, physical symptoms and signs are useful in identifying neonates with sepsis ${ }^{15}$.

Adjunctive therapy includes immunoglobulin, fresh frozen plasma, exchange transfusion, granulocyte transfusion, granulocyte colony stimulating factor and granulocyte macrophage colony stimulating factors, antilipid A monoclonal antibodies ${ }^{16}$.

Despite advances in antimicrobial treatment, outcomes of neonatal sepsis remain poor. Development of inexpensive and accessible interventions that could improve treatment outcomes and reduce case fatality is important ${ }^{7}$. Zinc is important for mucosal barrier function and components of innate and adaptive immunity, such as lytic activity of phagocytes and natural killer cells, and expression of cytokines. Short-term zinc supplementation decreased the bacterial load and reduced the NF-kB (nuclear factor kappa-light-chain-enhancer of activated B cells) activity in vital organs. Zinc is relatively non-toxic, but acute ingestion of large amount may cause liver and kidney failure, copper deficiency syndrome ${ }^{7}$.

One multicenter study in India using zinc as adjunctive therapy have shown significant reduction of neonatal mortality. They have reported that zinc reduced treatment failure in infants younger than 120 days with probable serious bacterial infection by $40 \% 7$. But other study in Nepal showed that adjuvant use of zinc does not decrease mortality rates, duration of hospital stay and requirement of higher antibiotic therapy in neonatal sepsis ${ }^{17}$.

\section{Materials and Methods}

This was a prospective, randomized double blind placebo controlled trial. This study was conducted during the period from 1st January 2013 to 31st December 2014. This study was conducted in the Department of Paediatrics, Sylhet M A G Osmani Medical College, Sylhet Bangladesh. All patients admitted with possible neonatal sepsis were the study population and those who fulfilled the inclusion criteria were enrolled as sample in this study. Systematic random sampling- every second case satisfying the inclusion criteria were enrolled in the study.

Sample size: was assuming attrition of $15 \%$, the calculated sample size was 65.6 or 66 in each group. But in this study 72 patients were taken in each group.

Age at admission: 3 to 28 days with weight between 2.5 to $4 \mathrm{Kg}$. Neonates presenting with any one or more of the following criteria plus positive blood culture report and/or CRP >10 u/L: (1) not feeding well, (2) convulsions, (3) fast breathing ( $\geq 60$ breaths $/ \mathrm{min})$, (4) severe chest In-drawing, (5) low body temperature (less than $35.5^{\circ} \mathrm{C}$ or $95.9^{\circ} \mathrm{F}$ ), (6) fever (more than $37.5^{\circ} \mathrm{C}$ or $99.5^{\circ} \mathrm{F}$ ), (7) movement only when stimulated or no movement at all and neonates with other problems like Necrotizing enterocolitis, Congenital anomaly, STORCH infection, perinatal asphyxia, Infants who could not tolerate feed within 24 hours of observation, Preterm baby, Low birth weight baby and those who already treated with second line drugs were excluded.

Procedure of data collection: All neonates admitted into the neonatal unit in the department of pediatrics were assessed for neonatal sepsis. Detailed antenatal, natal and post natal history were evaluated accordingly. Primarily neonates with clinical symptoms and signs of neonatal sepsis were enrolled in the study. A blood sample for culture and estimation of CRP was taken and sent to the laboratory. After getting the report if blood culture was negative and CRP was less than $10 \mathrm{u} / \mathrm{L}$, then patient was excluded from the study. Group allocation was done after fulfilling the enrolment criteria. They were divided into 2 groups: Group A and Group B. Zinc or placebo were prepared in identical packet. Each packet contained $5 \mathrm{mg}$ dispersible zinc sulphate or placebo. Zinc tablets were manufactured by Acme laboratories Ltd, Dhaka. Placebo was formulated by Crystalline Cellulose. Zinc and placebo were identical in appearance, consistency and taste. Separate code number was given by the head of the team and the code number was recorded in a preformed questionnaire. Each pack of zinc and placebo had been labeled with a unique serial number according to the randomization list, which was not available to the chief investigator until data had been obtained. Participants and investigators were masked to treatment allocation. Group allocation to either zinc or placebo group was done by lottery method which was marked as code- " $A$ " and code-"B". Antibiotic was administered according to standard national guideline for 7 days. Other supportive treatment was also given in both groups. One packet dissolved in $2.5 \mathrm{ml}$ expressed breast milk was given orally 
or through feeding tube to every infant 12 hourly for 7 days. The dose was repeated if infant vomits within 15 min of receiving the drug. Study physician examined patients for all relevant clinical features every 12 hours until recovery or end of day 7 .

The primary outcome was recovery from sepsis which was defined as absence of features of possible sepsis according to national guideline.

Data were recorded in a structured pre-formed questionnaire.

Decoding was done after completing data collection and then data analysis was done.

Ethical approval was obtained from Ethical committee of Sylhet M A G Osmani Medical College, Sylhet Bangladesh.

\section{Data collection and analysis}

Data analysis was done by using SPSS version 16.0 (statistical package for social science). Quantitative data were expressed as mean and standard deviation; and comparison was done between the groups by unpaired $t$ test. Qualitative data were expressed as frequency and percentage; and comparison were done by Chi-square $(\chi 2)$ test.

A probability value (p) of $<0.05$ were considered statistically significant.

\section{Results}

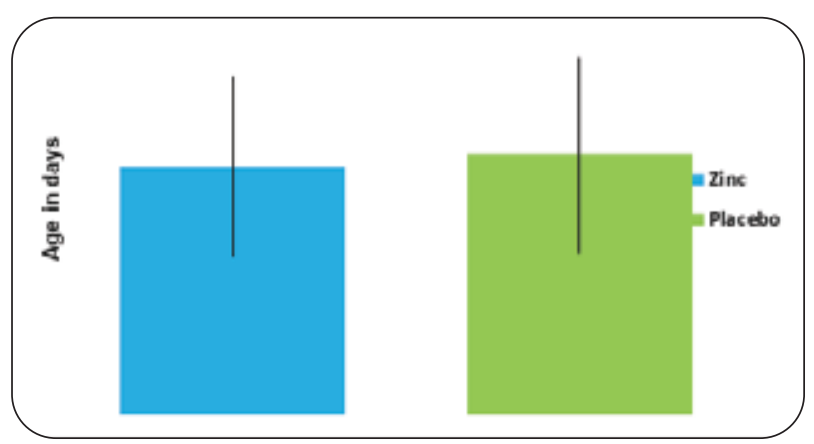

Figure-1: Comparison of the age of the patients between zinc group and placebo group

The age of the patients in zinc group and placebo group was $14.40 \pm 6.49$ days and $15.09 \pm 7.18$ days respectively. The age of the patients did not differ significantly between two groups $(\mathrm{t}=-0.576 ; \mathrm{p}=0.566)$.

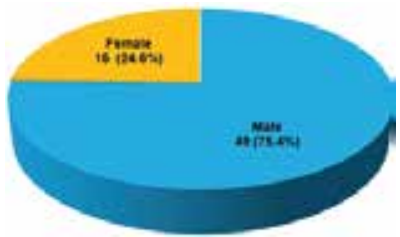

Zinc group $(\mathrm{n}=65)$

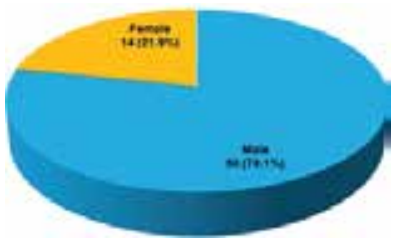

Placebo group $(\mathrm{n}=64)$
Figure-2: Comparison of sex of the patients between zinc group and placebo group
There were $49(75.6 \%)$ male neonates and $16(24.6 \%)$ female neonates in zinc group; while 50 (78.1\%) neonates were male and $14(21.9 \%)$ were female in placebo group. There was no significant difference in sex of the neonates between two groups $(\mathrm{p}=0.713)$.

Table-I: Comparison of the clinical presentations between zinc group and placebo group.

\begin{tabular}{llll}
\hline \multirow{2}{*}{$\begin{array}{l}\text { Clinical } \\
\text { presentations }\end{array}$} & \multicolumn{2}{c}{ Study group } & \multirow{2}{*}{-value } \\
\cline { 2 - 3 } & Zinc $(\mathrm{n}=65)$ & Placebo $(\mathrm{n}=64)$ & \\
\hline Not feeding well & $42(64.6 \%)$ & $48(75.0 \%)$ & $\mathrm{p}=0.199$ \\
Convulsion & $5(7.7 \%)$ & $3(4.7 \%)$ & $\mathrm{p}>0.05$ \\
Fast breathing & $30(46.2 \%)$ & $25(39.1 \%)$ & $\mathrm{p}=0.415$ \\
Severe chest in drawing & $8(12.3 \%)$ & $7(10.9 \%)$ & $\mathrm{p}=0.808$ \\
Low body temperature & $4(6.2 \%)$ & $6(9.4 \%)$ & $\mathrm{p}>0.05$ \\
Fever & $52(80.0 \%)$ & $50(78.1 \%)$ & $\mathrm{p}=0.794$ \\
Lathergy & $10(15.4 \%)$ & $16(25.0 \%)$ & $\mathrm{p}=0.173$ \\
\hline
\end{tabular}

The clinical parameters of not feeding well $(\mathrm{p}=0.199)$, convulsion ( $p>0.05)$, fast breathing $(p=0.415)$, severe chest indrawing $(p=0.808)$, hypothermia $(p>0.05]$, fever $(p=0.794)$ and lathergy (movement only when stimulated or no movement at all $)(\mathrm{p}=0.173)$ did not differ significantly between two groups.

Table-II: Comparison of the clinical outcome between zinc group and placebo group.

\begin{tabular}{llcl}
\hline \multirow{2}{*}{$\begin{array}{l}\text { Clinical } \\
\text { outcome }\end{array}$} & \multicolumn{2}{c}{ Study group } & \multirow{2}{*}{ p-value } \\
\cline { 2 - 3 } & Zinc (n=65) & Placebo (n=64) & \\
\hline Clinical recovery & $61(93.8 \%)$ & $59(92.2 \%)$ & $\mathrm{p}>0.05$ \\
Failure & $4(6.2 \%)$ & $5(7.8 \%)$ & \\
Total & $65(100.0 \%)$ & $64(100.0 \%)$ & \\
\hline
\end{tabular}

In zinc group clinical recovery was $61(93.8 \%)$ and failure in $4(6.2 \%)$ patients; while in placebo group clinical recovery was $59(92.2 \%)$ and failure in $5(7.8 \%)$ patients. There was no significant difference of clinical outcome between the zinc and placebo group [ $\mathrm{p}>0.05]$.

Table-III: Comparison of the clinical recovery time between zinc group and placebo group.

\begin{tabular}{lccc}
\hline \multirow{2}{*}{$\begin{array}{l}\text { Clinical recovery } \\
\text { time (hours) }\end{array}$} & \multicolumn{2}{c}{ Study group } & \multirow{2}{*}{ p-value } \\
\cline { 2 - 3 } & Zinc $(\mathrm{n}=65)$ & Placebo $(\mathrm{n}=64)$ & \\
\hline Mean & 104.20 & 111.46 & $\mathrm{p}=0.030$ \\
Standard deviation & \pm 16.61 & \pm 19.43 & \\
\hline
\end{tabular}

The mean clinical recovery time in zinc group was 104.20 \pm 16.61 hours and that of placebo group was $111.46 \pm$ 19.43 hours. Clinical recovery time was significantly earlier in zinc group that of placebo group $(p=0.030)$. 


\section{Discussion}

In this study age of the neonate of zinc group was $14.40 \pm$ 6.49 days and that of placebo group was $15.09 \pm 7.18$ days (Figure-1). The age of both groups was statistically similar $(\mathrm{p}=0.566)$.

In the present study $49(75.6 \%)$ male neonates and 16 (24.6\%) female neonates in zinc group; while 50 (78.1\%) neonates were male and $14(21.9 \%)$ were female in placebo group. There was no significant difference in sex of the neonates between two groups $(p=0.713)$ (Figure-2). Male neonates were predominant in both groups. This result correlated with the study of Bhatnagar et al. ${ }^{7}$ Mehta et al. ${ }^{17}$ also found similar pattern of gender distribution of neonatal sepsis.

Incidence of neonatal sepsis varies from 1 to 5 cases per 1000 live births in developed countries, but gets higher in developing countries which varies from 49 to 170 per $1000^{18}$.

In this study diagnosis of neonatal sepsis was primarily on clinical features. The clinical parameters did not differ significantly between two groups (table-I).

In the present study clinical recovery was $61(93.8 \%)$ and failure in $4(6.2 \%)$ patients in zinc group; while clinical recovery was $59(92.2 \%)$ and failure in $5(7.8 \%)$ patients in placebo group (Table-II). There was no significant difference of clinical outcome between the zinc and placebo group ( $\mathrm{p}>0.05)$. This result correlated with the study of Mehta et al. ${ }^{13}$ that mortality was $30(9.77 \%)$ in zinc group and $24(7.81 \%)$ in the placebo group and difference was not statistically significant $(\mathrm{p}>0.05)$. Similarly Bhatnagar et al. ${ }^{7}$ found $10(3 \%)$ treatment failure in zinc group and $17(5 \%)$ in placebo group with relative risk $=0 \cdot 57(0 \cdot 27$ to $1 \cdot 23)$ indicated that there was no significant difference of treatment failure rate between two groups.

In the current study the mean clinical recovery time in zinc group was $104.20 \pm 16.61$ hours and that of placebo group it was $111.46 \pm 19.43$ hours. Clinical recovery time was significantly earlier in zinc group than that of placebo group $(p=0.030)$. This result was different from the study of Bhatnagar et al. ${ }^{7}$ Where clinical recovery time did not differ significantly between zinc group and placebo group. They included neonates and infants in their study but the present study included only neonates of 3 to 28 days and this may be the cause of this difference. Mehta et al. ${ }^{17}$ found that the mean duration of hospital stay, $142.85 \pm 69.41$ hours in the drug group as compared to $147.99 \pm 73.13$ hours in the placebo group was also not statistically significant $(\mathrm{p}=0.841)$.

As adjunct treatment with oral rehydration for diarrhoea, zinc supplementation decreases duration and severity of the treated episode, and morbidity in the following 2-3 months ${ }^{19}$. Zinc has also reduced admissions to hospital and child deaths in community-based studies ${ }^{20,21}$. The benefits of zinc have been primarily reported in children with severe pneumonia episodes, ${ }^{22}$

In the current study adjunct zinc therapy reduced the time of clinical recovery. But clinical data also exist supporting a role for prophylactic zinc supplementation as a therapeutic strategy in infection related disease processes ${ }^{23}$.

The interpretation of this study would need to consider some potential limitations which include: It was a single center study, inability to estimate serum zinc levels in this study to rule out any underlying zinc deficiency prior to the onset of therapy.

\section{Conclusion}

In this study clinical recovery and failure rate did not differ significantly between zinc group and placebo group in neonatal sepsis. But the mean clinical recovery time was shorter in zinc group than that of placebo group.

\section{Recommendations}

Based on the findings of the present study recommends: Oral zinc may be given as adjunct treatment in neonatal sepsis, further study should be conducted involving multicenter and large sample to evaluate the effect of zinc as adjunct therapy in possible neonatal sepsis.

\section{Conflict of Interest: None.}

\section{Acknowledgement}

Dr. Tanjina Chowdhury, Assistant Professor, Department of Paediatrics, Sylhet MAG Osmani Medical College, Sylhet for his assistance in the analysis of data in this study.

\section{References}

1. Hakeem AEI, Jadba NEI, Yazji MSEI. Neonatal Septicaemia in Gaza City Hospitals. Pak J Med Sci. 2009; 25: 226-231.

2. Ghai OP, Gupta P, Paul VK. Essential Paediatrics. 6th ed. New Delhi: CBS Publishers; 2004.

3. Chan GJ, Baqui AH, Modak JK, Murillo-Chaves A, Mahmud AA, Boyd TK, et al. Early-onset neonatal sepsis in Dhaka, Bangladesh: risk associated with maternal bacterial colonisation and chorioamnionitis. Trop Med Int Health. 2013; 18:1057-1064.

https://doi.org/10.1111/tmi.12150

PMid:23822861

4. Khan MR, Rahman ME. Essence of Paediatrics. 4th ed New Delhi: Elseiver; 2011.

5. Ministery of Health and Family Welfare Government of the Peoples Republic of Bangladesh. National Neonatal Health Strategy and Guidelines for Bangladesh. Dhaka; 2009. 6. Mamun MMA, Billah M, Mistry SK, Nichols P, Dineen B, Nasreen HE. Maternal, neonatal and child health in northern districts of rural Bangladesh-profiling the changes during 2008-2010. Dhaka and Aberdeen: BRAC and Ipact (University of Aberdeen); 2012.

7. Bhatnagar S, Wadhwa N, Aneji S, Lodha R, Kabra SK, Chandra U, et al. Zinc as adjunct treatment in infants aged between 7 and 120 days with probable serious bacterial infection: a randomized, double -blind, placebo- controlled trial. Lancet. 2012; 379: 2072-2078.

https://doi.org/10.1016/S0140-6736(12)60477-2

8. Mollah MAH, Nahar N. Step on to Paediatrics. 2nd ed. Dhaka: Nitol Print; 2012. 
9. Movahedian AH, R Moniri, Z Mosayebi, Bacterial Culture of Neonatal Sepsis. Iranian J Publ Health. 2006; 35: 84-89.

10. Stoll BJ, Hansen N, Fanaroff AA, Wright L, Carlo WA, Ehrenkranz RA, et al. Late-onset sepsis in very low birth weight neonates: the experience of the NICHD Neonatal Research Network. Pediatrics. 2002; 110: 285-291.

https://doi.org/10.1542/peds.110.2.285

PMid: 12165580

11. Gordon A, Jeffery HE. Antibiotic regimens for suspected late-onset sepsis in newborn infants. Cochrane Database Syst Rev. 2005; (3): CD004501.

https://doi.org/10.1002/14651858.CD004501.pub2

PMid:16034935

12. Zaidi AK, Thaver D, Ali SA, Khan TA. Pathogens associated with sepsis in newborns and young infants in developing countries. Pediatr Infect Dis J. 2009; 28: S10-S18.

https://doi.org/10.1097/INF.0b013e3181958769

PMid: 19106757

13. Rubin LG, Sanchez PJ, Siegel J, Levine G, Saiman L, Jarvis WR, Pediatric Prevention Network. Evaluation and treatment of neonates with suspected late onset sepsis: A survey of neonatologists' practices. Pediatrics. 2002; 110: $42 \mathrm{e} 1-42 \mathrm{e} 7$.

https://doi.org/10.1542/peds.110.4.e42

PMid:12359815

14. The WHO Young Infants Study Group. Bacterial etiology of serious infections in young infants in developing countries. Pediatr Infect Dis J. 1999; 18: S17-S22.

https://doi.org/10.1097/00006454-199910001-00004

PMid:10530569

15. Jain NK, Jain VM, Masheshwari S. Clinical profile of neonatal sepsis. Kathmandu University Med J. 2003; 1: 117-120.

16. Dear P. Infection in the newborn. In: Rennie JM, Roberton NRC. Textbook of Neonatology. 3rd ed. Edinburg: Churchill Livingstone; 1999: 1109-1136.

17. Mehta K, Bhatta NK, Majhi S, Shrivastava MK, Singh RR. Oral Zinc Supplementation for Reducing Mortality in Probable Neonatal Sepsis: A Double Blind Randomized Placebo Controlled Trial. Indian Pediatr. 2013; 50: 390-393. https://doi.org/10.1007/s13312-013-0120-2

\section{PMid:23255688}

18. Li Z, Xiao Z, Li Z, Zhong Q, Zhang Y, Xu F. 116 cases of neonatal early-onset or late-onset sepsis: A single center retrospective analysis on pathogenic bacteria species distribution and antimicrobial susceptibility. Int J Clin Exp Med. 2013; 6: 693-699.

19. Fischer-Walker CL, Black RE. Zinc for the treatment of diarrhoea: effect on diarrhoea morbidity, mortality and incidence of future episodes. Int J Epidemiol. 2010; 39: S63-S69.

https://doi.org/10.1093/ije/dyq023

PMid:20348128 PMCid:PMC2845862

20. Baqui AH, Black RE, El Arifeen S, Yunus M, Chakraborty J, Ahmed S, et al. Effect of zinc supplementation started during diarrhoea on morbidity and mortality in Bangladeshi children: community randomised trial. BMJ. 2002; 325: 1059.

https://doi.org/10.1136/bmj.325.7372.1059

PMid:12424162 PMCid:PMC131175

21. Bhandari N, Mazumder S, Taneja S, Dube B, Agarwal RC, Mahalanabis D, et al. Effectiveness of zinc supplementation plus oral rehydration salts compared with oral rehydration salts alone as a treatment for acute diarrhea in a primary care setting: a cluster randomized trial. Pediatrics. 2008; 121: e1279-e1285.

https://doi.org/10.1542/peds.2007-1939

PMid: 18450870

22. Srinivasan MG, Ndeezi G, Mboijana CK, Kiguli S, Bimenya GS, Nankabirwa V, et al. Zinc adjunct therapy reduces case fatality in severe childhood pneumonia: a randomized double blind placebo-controlled trial. BMC Med. 2012; 10: 14.

https://doi.org/10.1186/1741-7015-10-14

PMid:22316073 PMCid:PMC3296597

23. Shankar AH, Prasad AS. Zinc and immune function the biological basis of altered resistance to infection. A Clin Nutr. 1998; 68: 447S-463S.

https://doi.org/10.1093/ajen/68.2.447S

PMid:9701160 